\title{
Infertility Care in the Netherlands for Turkish and Moroccan Migrants: The Role of Religion in Focus
}

\author{
Dineke G. Korfker ${ }^{1}$, Floor van Rooij ${ }^{2}$, Simone E. Buitendijk ${ }^{3}$, Symone B. Detmar ${ }^{4}$ \\ and Ria Reis ${ }^{5}$ \\ ${ }^{1,4}$ The Netherlands Institute for Applied Scientific Research (TNO), Leiden, the Netherlands \\ ${ }^{2}$ Faculty of Social and Behavioral Sciences, University of Amsterdam, Amsterdam, the Netherlands \\ ${ }^{3}$ Leiden University Medical Center (LUMC), Leiden, the Netherlands \\ ${ }^{5}$ Leiden University Medical Center (LUMC), Leiden, the Netherlands \& Amsterdam Institute for \\ Social Science Research (AISSR) University of Amsterdam, Amsterdam, the Netherlands
}

Correspondence should be addressed to: Dineke G. Korfker ; dineke.korfker@tno.nl

Received date: 19 january 2014; Accepted date: 15 May 2014; Published date: 18 July 2014

Academic Editor: Christos R. lavazzo

Copyright (C 2014. Dineke G. Korfker, Floor van Rooij, Simone E. Buitendijk, Symone B. Detmar and Ria Reis. Distributed under Creative Commons CC-BY 3.0

\begin{abstract}
Infertility treatments are difficult to understand, and doubly so for migrants because of religious and language factors. Previous studies showed that religion plays an important role in infertility care for Muslim couples that doctors do not always understand. The data presented here come from two exploratory studies that aimed to identify the main problems with infertility care for Turkish and Moroccan couples living in the Netherlands. In the first study, 105 Turkish, Moroccan and Dutch men and women were interviewed. In the second study, twenty general practitioners, gynaecologists and andrologists were interviewed by telephone. Additionally, three gynaecologists were interviewed in Morocco. A thematic analysis was conducted of the qualitative data. Almost all migrants had experienced problems with infertility treatments because they felt insecure about what was allowed by their religion. Moroccan men in particular doubt whether Dutch doctors are sufficiently acquainted with Islam and so they turn to Morocco for information and advice. Men stick to the rules and their agency is to follow the dictates of their religion. Women seem willing to be more flexible about the rules and navigate their agency. Doctors assumed that they took the religion of their patients into account, but they were not always fully aware of the importance of religious prohibitions. Others failed to take into account the agency of their patients. Conclusion: The situation in a new country challenges couples to shape their own agency in respect of reproductive treatment. Doctors are not always aware of the importance of religious doctrine about infertility treatment.
\end{abstract}

Keywords: Infertility care; Turkish and Moroccan Migrants; Islamic religion; Agency and Structure

Cite this Article as: Dineke G. Korfker, Floor van Rooij, Simone E. Buitendijk, Symone B. Detmar and Ria Reis (2014), " Infertility Care in the Netherlands for Turkish and Moroccan Migrants: The Role of Religion in Focus" Obstetrics \& Gynecology: An International Journal, Vol. 2014 (2014), Article ID 913057, 


\section{Introduction}

Worldwide infertility is a problem for couples of reproductive age. Due to different definitions of infertility, the prevalence rate varies (Culley, Hudson \& van Rooij 2009). A recent review of 25 surveys on infertility concluded that about 9 per cent of women in the 20-44 age group experience infertility, which is defined as the failure to conceive after a year of regular intercourse without contraception. This results in a figure of 72.4 million women worldwide (Boivin et al. 2007). This study also found remarkably similar rates in countries at different stages of development. However, the causes of infertility vary between countries. Most infertility in Africa, for example, is due to reproductive tract infections from sexually transmitted diseases, unsafe abortions and poor postpartum care (Inhorn 2003). In Western countries, infertility related to the advanced age of mothers is an important cause of infertility, while this is infectious diseases in underdeveloped countries (Culley, Hudson \& van Rooij 2009).

Couples seek different solutions for their fertility problems, but they usually seek help sooner or later. The availability of services is an important pre-condition here. Seeking help can take many forms and is not restricted exclusively to medical services. When biomedical services are not available people turn to traditional healers (i.e. "Complementary and Alternative Medicine" - CAM) (Smith et al. 2011). However, this pattern is not found only when biomedical services are lacking, as shown by a study in the US, where a substantial minority (29\%) of infertile couples turn to CAM, with wealthier couples doing so more often (Smith et al. 2011). In Turkey, people use traditional therapies beside their normal medications as a support for the conventional medical therapy and not as a substitute (Edirne et al. 2010). In developing countries, the biomedical services are often less developed and when they are available, they are affordable only for the rich (Inhorn 2003).

Infertility treatment often starts with less invasive biomedical/medical techniques such as hormone therapy or insemination with semen from the partner. If these methods prove unsuccessful, there is a wide range of other Assisted Reproductive Technologies (ART) on offer. The development of In Vitro Fertilisation (IVF) in England in 1978* was an enormous step forward. IVF was refined with the introduction of IntraCytoPlasmic Sperm Injection (ICSI) in the early nineties, which made it possible to use only one spermatozoid to fertilize the oocyte. Infertility treatments are difficult to understand due to the complexity of the medical procedures. In addition, couples with fertility problems have to think about how far they will go with the treatments on offer. Many studies describe how people are drawn into a kind of 'medical treadmill' and feel overwhelmed by a dynamic that they feel they cannot fully control (Becker 2000). Gerrits describes this phenomenon in a study of couples at a fertility clinic in the Netherlands (Gerrits 2008).

Infertility treatments are difficult to understand due to the complexity of the medical procedures. This is true for all patients, but particularly so for nonwestern migrants** because of cultural differences and language problems. For migrants, another issue that should be addressed is that migrants often have different views about appropriate fertility care. Their decisions about infertility treatment are influenced by their social and cultural backgrounds, and they are also influenced by the social and cultural environment of their new country (van Rooij 2008). Religion, as an important element of the cultural background, is assumed to affect how people approach infertility (Fadel 2002, Hathout 2006, Schenker 2005, Serour 2008).

This article focuses on the role of religion in infertility treatment for couples from the two largest Muslim ethnic minorities in the Netherlands, Turks and Moroccans. How are religious prohibitions interpreted if they limit their reproductive options? How do couples navigate the religious rules and how do they make their own choices and perhaps reframe religious prescriptions in the light of their wish to have children? And how does the social environment in their 
new country affects their decisions about fertility treatment?

The article presents data relating to these issues as part of a larger qualitative study examining migrant women's experience of reproductive health care, and specifically infertility treatment (Korfker et al. October 2008)(Korfker et al. October 2008).

\section{Islamic Reproductive Law: the Formal Structure}

The principal primary sources for sharia (Islamic law governing the lives of Muslims) are the Qur'an and Hadith. They affirm the importance of marriage, family formation and procreation (Fadel 2002). Infertile couples are therefore instructed and encouraged to seek a cure for their infertility, but within the limits of what is permissible under sharia (Serour 1993, Atighetchi 2000b). Islam does not allow all biomedical treatments. There are several authoritative religious decrees - "fatwas" relating to assisted reproductive technologies (ARTs) that prohibit several methods. Initially, the attitude of Muslim jurists was very critical if not hostile (Atighetchi 2000b). Fertility and sterility were considered to be the result of divine will (Koran 42, 49-50) and all reproductive methods other than natural methods were therefore to be avoided (Atighetchi 2000b, Arbach 2002). On the basis of these assumptions, even homologous artificial insemination (i.e. insemination with the partner's sperm) was forbidden in the opinion of some Islamic Scholars (Atighetchi 2000b). Following the initial prohibition of ARTs by fatwas, ART became more widely accepted since medically assisted reproduction contributes to the stability and continuity of married life. The Sheikh of Cairo's Al-Azhar University (the most authoritative in the Sunni Muslim world), was positive about ART's in a fatwa in March 1980 (Inhorn, Patrizio 2012). However, sharia still imposes limits and these limits are basically respected by positive laws in different countries (Hathout 2006, Serour 1993, Atighetchi 2000a, Atighetchi 1994, Larijani, Zahedi 2007). Some important points of reference were established in the guidelines formulated at the end of the first international conference on 'Bioethics in Human Reproduction in the Muslim World' in 1991 at the International Islamic Center for Population Studies and Research, AlAzhar University, Cairo. In 2000, a workshop organised by the same institute confirmed earlier recommendations for a Standing Committee for Sharia Medical Ethics to monitor and assess developments in ART practice (Serour, Dickens 2001). For example, ART involving donated gametes is not permitted in Sunni Islam (which includes approximately 90 per cent of the world's Muslims). No gametes from a third party are permitted to enter into the marital functions of sex and procreation (Smith et al. 2011, Atighetchi 2000a, Serour, Aboulghar \& Mansour 1995, Meirow, Schenker 1997, Inhorn 2006b, Yeprem 2007). Family and blood relations in Islam have very important legal implications. Marriage and inheritance laws are well defined on the basis of these family relationships. The use of donor sperm, donor eggs, or donor embryos would result in a biological father or mother who is not one of the "married couple". Under Islamic law, this would be comparable to adultery (Fadel 2002), threatening the "purity of the lineage" (Serour, Aboulghar \& Mansour 1995). Artificial insemination with the husband's semen is permitted if insemination occurs while the marriage is intact. The husband's frozen semen cannot therefore be used after divorce, or after the husband's death. Islam also does not favour adoption and surrogacy, which is forbidden by Sharia. Offspring, independently of the type of fertilisation, must be the fruit of the biological and legally married mother and father. This prohibition is respected by virtually all Muslim countries (Atighetchi 2000a). Since the late 1990s, however, divergences in opinion over third-party gamete donation have occurred between Sunni and Shi'ite Muslims. The Shi'ite Iranian leading ayatollah was permitting gamete donation (under certain conditions) (Inhorn 2006c). As a result, adoption and gamete donation are available in Iran and Lebanon, two Middle Eastern countries with significant Shi'ite Muslim populations (Larijani, Zahedi 2007, Inhorn 2006d). Adoption is also allowed by 
law in Turkey, which is a secular state (Culley, Hudson \& van Rooij 2009).

Fertility treatment requires masturbation for the production of sperm. The Quran and the Hadith do not mention masturbation directly, but it is not encouraged in most Islamic law traditions. However, there is no moral objection in Islam to masturbation if the ultimate purpose is insemination or artificial insemination (Atighetchi 2000a). Another sensitive point is that Islam does not allow male doctors to see women's genitals and so female doctors are preferred.

\section{Method and Theoretical Framework}

The data presented come from two qualitative studies with the aim of identifying the main problems in infertility care for Turkish and Moroccan couples in the Netherlands. For the first study, ethical approval was obtained by the medical ethical commission of the Leiden University. In this study, 81 Turkish and Moroccan men and women being treated by gynaecologists and andrologists (doctors for male uro-genital problems) were interviewed in their homes, separately by migrant outreach workers, who were matched to the participants by gender and ethnicity. A Dutch reference group $(n=24)$ receiving the same treatment was also interviewed. Interviews took place with eight Turkish, 31 Moroccan and ten Dutch men, and 21 Turkish, 21 Moroccan and 14 Dutch women. Due to the sensitivity of the subject, recruitment was highly complicated, especially among Turkish men. The interviewers were Turkish and Moroccan male and female outreach workers with an extra training in interview technics. The interviewers succeeded in recruiting 67 per cent $(n=70)$ of the study population through the snowball method (sampling technique where existing study subjects recruit future subjects); 33 per cent $(n=35)$ were recruited through doctors in the hospital.

A semi-structured questionnaire in Dutch based on previous studies of infertility in migrants was drawn up, with a combination of open-ended and closed questions. The Turkish and Moroccan interviewers were able to help in case of language problems. The questionnaire was different for men and women, because some questions specifically addressed male or female health issues.

The answers to the closed questions of the questionnaires were analysed with SPSS 17.0 using descriptive statistics. The answers to the open-ended questions were written down verbatim. The texts were coded and arranged and analysed on the basis of themes.

The second study investigated doctors' views of problems in infertility care by interviewing general practitioners, gynaecologists and andrologists in the Netherlands and in Morocco.

In the Netherlands telephone interviews with open-ended questions were conducted with eight gynaecologists, three andrologists and nine general practitioners. They were asked about the main problems they experienced in infertility care for Turkish and Moroccan couples by comparison with Dutch patients. The interviews were recorded, written out verbatim, coded and analysed on the basis of themes. In Morocco, three gynaecologists were interviewed using open-ended questions about experiences of Moroccans with infertility treatments in the Netherlands. It was not possible to record these interviews due to logistical restrictions. These interviews were summarised by the Moroccan interviewer and analysed on the basis of themes by the researchers.

Practice theory as described by Ortner (Ortner Sherry B. 2006) was used as a theoretical framework to analyse how Muslim men and women navigate the seemingly rigid structures of their religion relating to procreation. Practice theory describes how social subjects through their behaviour in the world can change their world. The production of the world through human practice is a concept that provides on the one hand "structure" and on the other hand "agency" (Ortner Sherry B. 2006). "Agency" refers to the capacity of individuals to act intentionally and to make their own free choices. "Structure" are 
those factors of influence (such as social class, religion, gender, etc.) that determine or limit an agent and his or her decisions (Barker 2005).

The central theme we will discuss in this article is that migrants in their new social environment navigate the "structure" of their religious prescriptions and the "agency" they can create for themselves, in other words the practice of their decisions. They incorporate elements of their new social and cultural environment in this process. By analysing the results of our study of the impact of religion on infertility treatments, from a medical perspective as well as a patient perspective, we will shed light on these issues. Religion, since it concerns itself with affairs that are regarded as extraordinarily important in life, is an intrinsic part of the cultural framework of each society. It is important for practitioners in the field of reproductive medicine to understand attitudes towards reproduction that derive from different religions (Schenker 2005). Related to the position of doctors we pay attention to the concept of cultural essentialism that "exaggerates the unity of cultures..." and that tends to deny "agency" to members of minority ethnic group (Culley, Hudson 2009).

\section{Study Results}

\section{The Study Population}

The mean age of the male respondents was 35.4 years old (Moroccans 35.4, Turks 36, Dutch 35.4) and the mean age of the female respondents was 31.7 (Moroccans 30.2, Turks 33.1, Dutch 33.5). Table 1 shows the length of stay in the Netherlands. Only 16\% of the migrants in the study population were born in the Netherlands (second generation) and $20 \%$ had been living in the Netherlands for less than seven years. The majority had been living in the Netherlands for periods of time ranging from eight years to upwards of 25 years (64\%).

Table 1: Percentages for length of stay in the Netherlands

\begin{tabular}{|c|c|c|c|c|c|}
\hline $\begin{array}{l}\text { Length of } \\
\text { stay }\end{array}$ & $0-7 y$ & $8-15 y$ & $16-25 y$ & $>25 y$ & Born in Neth. \\
\hline $\begin{array}{l}\text { Moroccan } \\
\text { women }\end{array}$ & 1 & 28 & 24 & 24 & 5 \\
\hline $\begin{array}{l}\text { Moroccan } \\
\text { men }\end{array}$ & 19 & 13 & 39 & 6 & 23 \\
\hline $\begin{array}{l}\text { Turkish } \\
\text { women }\end{array}$ & 5 & 28.5 & 24 & 28.5 & 14 \\
\hline Turkish men & 63 & 0 & 12 & 0 & 25 \\
\hline Total & 20 & 20 & 28 & 16 & 16 \\
\hline
\end{tabular}

The percentage of respondents with low education (no education and primary school) was higher among Moroccan and Turkish women and Turkish men (48\%,
$38 \%, 38 \%$ ) than among Moroccan men and Dutch men and women (9\%, 0\%, 10\%). People were not asked about their religion, but the interviewed migrants referred to Allah in their answers. Specifically, they 
were asked whether religion had an impact on their fertility treatment.

\section{Adaptability within the Structure of Religion}

The impact of Islam on fertility treatment was substantial in our study population and therefore exemplary for the influence of the structure of Islam in the field of procreation. Only one-fifth of Dutch couples said that religion played a role in the sense that they trusted God to take care of their problems, but that religion did not have an impact through commandments or prohibitions. However, the majority of Turks and Moroccans argued that the almighty wisdom of Allah determines how infertility problems should be approached. They believed that Allah has the power to decide whether they will have children. The majority of the Moroccan men and less than half of the Turkish men answered that religion affected their approach to fertility treatment. One-third of the Turkish and Moroccan women thought their infertility treatment was influenced by religion.

When describing the impact of religion, Turks and Moroccans indicated how they struggled with the structure prescribed by religion. From the data it is clear that religion is the norm in their decisions about the treatment. Turkish women said that religion led to a preference for a female doctor and the refusal of semen and gamete donation. Moroccan men found it difficult to know what is required by Islam. They expressed a concern about treatments being forbidden by religion and described feelings of uncertainty because they did not know what was allowed. 'Before $a$ treatment starts I have to know if it is allowed by Islam', and when the treatment is not allowed: 'My faith comes before my wish to have a child'. They do not trust Dutch doctors to know which treatments are acceptable under Islam. All Moroccan men who answered the question 'Do you think Dutch doctors take your religion into account in their treatment' responded negatively. One-fifth of the Moroccan and Turkish women and more than half of the Turkish men also thought that Dutch doctors did not take their religion into account in their treatment. When asked why not, the majority of Moroccan men answered 'I don't know, but I don't think so'. It was also said that 'they never asked anything about my religion'.

Most people want confirmation about what their religion allows. Many therefore visit an imam for advice. Moroccan couples even return to their home country and consult doctors in Morocco about which treatments are acceptable for Muslims. Almost half of the Moroccan women said they had gone to Morocco for help, mainly in the form of information and medical analyses. Only one said that she had been to Morocco for medical treatment. Most women go to find out which treatments are forbidden by Islam. The situation among Turkish migrants is different. A majority of the Turkish women go to Turkey for help, mainly for medical analyses and treatment rather than for information.

Seeking help in the country of origin was not related to length of stay in the Netherlands.

Three Moroccan fertility doctors interviewed in Rabat and Meknes in Morocco stressed the uncertainty of couples who consult them about their treatment in the Netherlands. A female Moroccan doctor: "the reason people come to me in Morocco is that they do not understand their treatment in the Netherlands. But their religion is even more important. They are afraid that doctors in the Netherlands do not take their religion into account in their treatment. In Islam, sperm donation is forbidden and they are worried that the doctor may use the sperm of another man".

Uncertainty about the attitude of the doctor engenders a lack of trust. This is made clear by the fact that one-third of the Moroccan and Turkish women do not trust their treatment, whereas we found only one Dutch woman who did not trust her treatment. A quarter of the Moroccan and Turkish men answered that they had doubts about their treatment. 


\section{Do People Shape their Own "Agency" in Fertility Treatment?}

The prohibition of third-party gamete donation is an important issue in either the acceptance of "structure" or making use of "agency". In practice, the use of a donor for semen was accepted only once by a woman and the use of a donor ovum was never mentioned by the interviewed men and women in our first study. Several women mentioned insemination with donor semen as their last resort, but their husbands did not accept it.

A Moroccan woman said "My husband said it should come on its own and it would be wrong for me to get semen from another man." And another Moroccan woman: "If the next treatment isn't successful, I am thinking about donor semen, even though my husband doesn't agree."

A Turkish woman said "Eventually, when treatment in the Netherlands was unsuccessful, we went to Turkey for treatment, which was unsuccessful as well. The only solution would be donor semen, but my husband doesn't want to talk about that." And another Turkish woman: "I would have liked to opt for donor semen..."

The majority of Moroccan and Turkish men said that they only did what was allowed by their faith: "I accept only treatment allowed by my religion", while only a few women said the same. In the examples quoted above, women seem willing to use donor semen, but men do not.

However, although donor sperm and eggs were never mentioned in the interviews, Dutch doctors did talk about using donor sperm and donor eggs.

Insemination with the husband's semen was practised to some extent by all groups. Turkish and Moroccan men and women expressed abhorrence at the idea of using other men's semen for insemination.

The need to produce semen by masturbation for analysis was another cause for religious concern of the respondents. They wanted permission from the imam because they were uncertain if masturbation is allowed by Islam.

Two gynaecologists and an andrologist said that semen was sometimes delivered with a condom in the jar after having been obtained by intercourse to avoid masturbation. The men mentioned the problem of producing semen in the hospital: "everybody sees you going into the special room". They would prefer to produce semen at home.

A Moroccan doctor gave a non-religious explanation of the reluctance to deliver semen for analysis: the male reluctance to be a subject of infertility research. "They think their wives are responsible for fertility problems and so they don't see the need to produce semen for analysis". This Moroccan doctor said that some men would rather marry another woman than be examined. A GP in the Netherlands also mentioned the reluctance of men to have their sperm tested.

The majority of the Turkish and Moroccan men said they were alone during masturbation. Remarkably, almost half of the Turkish and Moroccan women reported they were present. Half of both Dutch men and women reported that they were present. This might be an indication of how sensitive the issue was for Turkish and Moroccan couples. One third of the Moroccan women said their husbands had problems because they could not get excited without their wives being present.

The gender of health-care staff was important for Moroccan patients. A majority said they wanted a gendermatched doctor. More than two-thirds of Moroccan women and more than one-third of the Turkish women wanted a female doctor. More than half of the Moroccan men had a strong preference for a male doctor for themselves. In our study Moroccan and Turkish men want a female doctor for their wives and some would even refuse a male doctor. Knowledge of Dutch and length of stay was not related to these opinions. Interestingly, more than half of the Dutch reference group also preferred a female doctor: women for 
themselves and men for their wives. This was not a religious issue but more because they felt more at ease with a doctor of their own gender.

\section{Health Practitioners Observe "Agency"}

General practitioners, gynaecologists and andrologists were asked about the influence of religion in treatment for migrants. The general practitioners said they could not easily distinguish between cultural and religious influence. More than half of the gynaecologists and andrologists did not see Islam as a factor in the acceptance of fertility treatment. The other half did find that religion played a role. Some doctors said this was a positive influence: "in the end, they accept their childlessness because they see it as the will of Allah". Difficulties with a male doctor were mentioned by Dutch doctors as one effect of Islam. Others mentioned the fact that not all treatments were accepted and the uncertainty about what was permitted under Islamic law; "It happens that people first consult an imam", was the observation made by these gynaecologists and andrologists. Two general practitioners did find that donor insemination was a problem; but one doctor had several couples who accepted donor insemination but kept it secret from their families. Three gynaecologists and one andrologist also had patients who accepted donor insemination. One doctor noticed that donor insemination was even more difficult for Turks than for Moroccans. Only one gynaecologist had experience with ovum donation and noted that: "Ovum donation is accepted more easily than semen donation; they choose a family member or a good friend, although sometimes we have the impression they come with a stranger and pay the donor. They want to keep semen donation a secret". One gynaecologist had the impression that the acceptance of donor sperm was increasing. The interviewed doctors usually seem to inform their patients about the possibility of insemination with donor sperm or the use of a donor ovum, but this is not always clear. They said several times that it was difficult to raise the issue. Some answers such as "we don't do it in the hospital" or "it is a taboo" - were difficult to interpret.
However, doctors mentioned the acceptance of donor insemination several times and a donor ovum once, while only one of the interviewed patients did. It is not clear whether doctors offer their migrant patients the option of donor gametes.

\section{Discussion}

Numerous requirements and prohibitions in Islam regarding ART make it very complicated for Islamic couples receiving fertility treatment to make the relevant decisions. Their position as migrants living in a Western country results in extra problems. The available methods in Western countries do not comply with religious dictates and go beyond what is acceptable for Muslims. Doctors in the countries of origin are able to advise on the basis of Islamic structures, giving the couples a sense of security. The data from our study show that many migrants have doubts about their medical treatment and that they are unsure whether it complies with Islamic fatwas. This raises the question of the extent to which religion is a factor in the answers of the Turkish and Moroccan respondents.

Dutch doctors think they know what is permitted by Islam but it is not clear whether they sometimes adapt their treatment accordingly by not offering forbidden methods. However, although the doctors we interviewed were aware of Islamic rules about the third-party donation of gametes, they still offer these "forbidden" methods to their patients and as such accept "agency" of their patients. In Van Rooij's study, several Turkish people expressed dissatisfaction about their doctors proposing the semen or egg donation (van Rooij, Korfker 2009). However, others complained that the doctor did not allow them to make their own decision about whether or not to use donor eggs or donor semen, and that the doctor made assumptions about their behaviour on the basis of their stated religious beliefs (Atighetchi 1994, Serour, Dickens 2001, Yeprem 2007, Inhorn 2006d, van Rooij, Korfker 2009, van Rooij, van Balen \& Hermanns 2009). Although Sunni Islam does not allow egg or semen donation, a couple may nevertheless decide 
to avail themselves of this option. By not proposing the possibility of gamete donation, the doctor denies the agency of the patients and effectively precludes them from taking their only chance of achieving a pregnancy (van Rooij, Korfker 2009). In Van Rooij's study of help-seeking patterns and decision-making, she finds that 21 per cent of women and 5 per cent of men mentioned that they would accept male donor semen if this was necessary to have a child. The acceptance of egg donation is higher in both groups: 27 per cent of women and 20 per cent of men (van Rooij, Korfker 2009). A Turkish survey of the opinions of infertile Turkish women about gamete donation found that some infertility patients approve of gamete donation: 23 per cent were for accepting oocytes and 3.4 per cent were for accepting sperm (Baykal et al. 2008). Another Turkish study focused on oocyte donation. Only 15 per cent of the respondents were completely opposed to oocyte donation and more men were in favour than women (Isikoglu et al. 2006). These are examples of women and men who explore their own agency in a society dominated by Islam by negotiating the structure that prohibits the third-party donation of gametes. However, Khalili describes a study from Iran and Turkey where the majority thought that oocyte donation was allowed by their religion (Khalili et al. 2008). In our study, women mentioned the reluctance of their husbands to accept donor semen, while they themselves seemed to be in favour. Just as in the examples of Van Rooij and Baykal, the agency of women seem to negotiate with the prevailing structure, while the agency of men looks to comply with this structure in accordance with their religion. Simpson describes this process in a study among Pakistani in England as:

"a complex navigation through demands placed on couples by religion, community, the medical profession and by husbands and wives themselves upon each other." (Simpson, Hampshire \& Blell 2012). They use the notion of "moral pioneering" first put forward by the anthropologist Rayna Rapp as an explanatory model for the efforts of couples to work out an optimal social and cultural position in relation to infertility.

The data in our study also show a mismatch between men and women with respect to the acceptance of gamete donation: women said their husbands did not accept gamete donation while they themselves seem to see it as a last-chance option. They did not openly say that they were in favour of donor insemination, but by saying only that their husbands were opposed, they seemed to suggest that they themselves were not. Women's strong wish to have a child, amplified by the social norms about procreation, means they adopt a more flexible approach to the prohibitions of their religion and therefore explore their agency to fulfil their serious desire for offspring child. According to the information from the doctors, some couples choose to challenge structures by breaking the rules relating to third-party donor gametes and decide to accept donor gametes while keeping this a secret from their families. People did not admit openly in our study that they accepted donor gametes, except for one woman who admitted third-party donation. Secrecy about gamete donation seems to be one way Islamic couples extend their agency. We do not know whether men use the structural reason of religious regulation as an opportunity to escape the burden of being seen as infertile and to evade the corresponding questioning of their virility. Further research is needed to answer this question.

Inhorn investigated the attitudes of childless Muslim men in Lebanon towards both adoption and gamete donation (Inhorn 2006a). Most Muslim men continue to resist both, arguing that such a child "won't be my son". However, some Muslim men are adopting these alternatives as ways of preserving their loving marriages, of satisfying their desires to be fathers, and of challenging religious dictates (Inhorn 2006a). Men in our study did not admit that they were considering gamete donation: the topic was never mentioned by men. 
Several studies indicate that patients' Islamic beliefs may also play a role in women's preference for a female doctor (Atighetchi 2000b); (Lafta 2006); (Yanikkerem et al. 2009). Our study found a preference for female doctors among Moroccan women and men that was less pronounced among Turks. Van Rooij also found in her study that Turks seldom raise the issue of gender-matched doctors (van Rooij, Korfker 2009). In our study, we did not enquire explicitly about the reasons for gender preference and so it may be that non-religious reasons also played a role. Indeed, the Dutch reference group also had a gender preference. However, the strong preference for a woman doctor in the Moroccan group, which even extended to the refusal of a male doctor by some husbands, suggests that religion is very important for Moroccan men in their preference for a female doctor for their wives. This preference for gender matching therefore seems necessary to maintain the dominant religious structure, especially for Moroccan men and to a lesser extent for Moroccan women.

Men were hesitant about the production of semen by masturbation because of the assumed prohibition in Islam on masturbation in general. They had to consult the imam for permission, and to avoid masturbation, some couples provided semen by making use of a condom during intercourse. Inhorn has provided an extensive description of the ambivalence toward semen as simultaneously life-giving and polluting and toward masturbation as a defiling and repugnant in Muslim societies (Inhorn 2007);(Khuri 2001). Furthermore, the act is surrounded by guilt and sometimes men assume that their infertility is a result of masturbating as a child (Inhorn 2007). A Moroccan population-based epidemiological study of women's sexual behaviour found that 90 per cent of the women thought masturbation was forbidden, and that 83 per cent associated it with guilt and shame, but 15 per cent thought that it was authorised by religion as a means of calming the effects of abstinence (Kadri et al. 2007).
There were several limitations in our study. More than half of the interviewees were recruited by the interviewers, and this may have led to some bias in the answers. The interviewers convinced people to participate by telling them that being interviewed was an opportunity to express the problems they experienced. The number of Turkish men who participated in the study fell short of the target. Interviewers from the individual ethnic communities on the one hand may have created a better understanding during the interview, but on the other hand this also may have limited participant openness because of a fear of gossiping in the community. This raises the question of the extent to which religion is a factor in the answers of the Turkish and Moroccan respondents.

\section{Conclusion}

Many migrants have problems with infertility treatments because a large group feels insecure about what is allowed by their religion. This is particularly true of Moroccan men. They doubt whether doctors are sufficiently acquainted with Islam. Moroccans therefore go to Morocco for information and advice. Moroccan doctors confirm these facts and would like to advise European doctors on the subject.

Doctors assume they take the religion of their patients into account, but are not always aware of the importance of religious prohibitions for fertility treatment. Others take the rules too literally and do not take the agency of their patients into account.

Men cling to the rules and their agency is to comply with what structure prescribes; women may prefer to adapt the rules and navigate their agency, and even disregard the preferences of their husbands. The situation in a new country challenges couples to shape their own agency. This may result in the acceptance of more gamete donations. Doctors need to be educated in cultural competency so that they are aware of these dynamics and can help their migrant patients. 


\section{Acknowledgements}

We thank the Netherlands Organisation for Health Research and Development for financing this study.

Survey forms (in Dutch) can be obtained by sending an email to the author dineke.korfker@tno.nl

\section{Notes}

* In the Netherlands, the first successful IVF treatment was in 1983 (Hardon 2003). Three IVF attempts are paid by the health insurance.

** Dutch definition of migrant (allochtoon): anyone who had at least one parent born outside the Netherlands. If a person is born in the Netherlands he/she is second generation migrant. Non-western countries are countries in Africa, Latin America, Asia (except Japan and Indonesia) and Turkey (Statistics Netherlands).

\section{References}

1. Arbach, 0. 2002, "Ethical considerations in Syria regarding reproduction techniques", Medicine and law, vol. 21, no. 2, pp. 395-401.

2. Atighetchi, D. 2000a, "Islamic tradition and medically assisted reproduction", Molecular and cellular endocrinology, vol. 169, no. 1-2, pp. 137-141.

3. Atighetchi, D. 2000b, "Islamic tradition and medically assisted reproduction", Molecular and cellular endocrinology, vol. 169, no. 1-2, pp. 137-141.

4. Atighetchi, D. 1994, "The position of Islamic tradition on contraception", Medicine and law, vol. 13, no. 7-8, pp. 717725.

5. Barker, C. 2005, "Cultural Studies: Theory and Practice. London: Sage. ISBN 07619-4156-8 p448" in Cultural Studies: Theory and Practice, ISBN 0-7619-4156-8 edn, Sage, London, pp. 448.
6. Baykal, B., Korkmaz, C., Ceyhan, S.T., Goktolga, U. \& Baser, I. 2008, "Opinions of infertile Turkish women on gamete donation and gestational surrogacy", Fertility and sterility, vol. 89, no. 4, pp. 817822.

7. Becker, G. 2000, The elusive embryo: how women and men approach new reproductive technologies. , Berkeley and London: University of California Press.

8. Boivin, J., Bunting, L., Collins, J.A. \& Nygren, K.G. 2007, "International estimates of infertility prevalence and treatmentseeking: potential need and demand for infertility medical care", Human reproduction (Oxford, England), vol. 22, no. 0268-1161; 0268-1161; 6, pp. 1506-1512.

9. Culley, L., Hudson, N. \& van Rooij, F. 2009, "Ethnicity, Infertility and Assisted Reproductive Technologies" in Marginalized Reproduction; Ethnicity, Infertility and Reproductive Technologies, eds. L. Culle, N. Hudson \& F. van Rooij, Earthscan, London, pp. 1-14.

10. Culley, L. \& Hudson, N. 2009, "Commonalities, Differences and Possibilities: Culture and Infertility in British South Asian Communities" in Marginalized Reproduction; Ethnicity, Infertility and Reproductive Technologies, eds. L. Culley, N. Hudson \& F. van Rooij, First edn, Earthscan, UK and USA, pp. 97116.

11. Edirne, T., Arica, S.G., Gucuk, S., Yildizhan, R., Kolusari, A., Adali, E. \& Can, M. 2010, "Use of complementary and alternative medicines by a sample of Turkish women for infertility enhancement: A descriptive study", $B M C$ Complementary and Alternative Medicine, vol. 10.

12. Fadel, H.E. 2002, "The Islamic viewpoint on new assisted reproductive technologies", The Fordham urban law journal, vol. 30, no. 1, pp. 147-157.

13. Gerrits, T. 2008, Clinical Encounters. Dynamics of patient-centred practices in a Dutch fertility clinic, Faculty of Social and 
Behavioural Sciences; University of Amsterdam.

14. Hardon, A. 2003, "Reproductive health care in the Netherlands: Would integration improve it?", Reproductive health matters, vol. 11, no. 21, pp. 59-73.

15. Hathout, H. 2006, "An Islamic perspective on human genetic and reproductive technologies", Eastern Mediterranean health journal $=$ La revue de sante de la Mediterranee orientale = alMajallah al-sihhiyah li-sharq al-mutawassit, vol. 12 Suppl 2, pp. S22-S28.

16. Inhorn, M.C. 2006a, ""He won't be my son": Middle Eastern Muslim men's discourses of adoption and gamete donation", Medical anthropology quarterly, vol. 20 , no. 1, pp. 94-120.

17. Inhorn, M.C. 2006b, ""He won't be my son": Middle Eastern Muslim men's discourses of adoption and gamete donation", Medical anthropology quarterly, vol. 20 , no. 1 , pp. 94-120.

18. Inhorn, M.C. 2006c, "Making Muslim babies: IVF and gamete donation in Sunni versus Shi'a Islam", Culture, medicine and psychiatry, vol. 30, no. 0165-005; 0165005; 4, pp. 427-450.

19. Inhorn, M.C. 2006d, "Making Muslim babies: IVF and gamete donation in Sunni versus Shi'a Islam", Culture, medicine and psychiatry, vol. 30, no. 0165-005; 0165005; 4, pp. 427-450.

20. Inhorn, M.C. 2003, "Global infertility and the globalization of new reproductive technologies: illustrations from Egypt", Social science \& medicine (1982), vol. 56, no. 9, pp. 1837-1851.

21. Inhorn, M.C. \& Patrizio, P. 2012, "The global landscape of cross-border reproductive care: Twenty key findings for the new millennium", Current Opinion in Obstetrics and Gynecology, vol. 24, no. 3, pp. 158-163.

22. Inhorn, M.C. 2007, "Maturbation, Semen Collection and Men's IVF Experiences:
Anxieties in the Muslim World", $B \& S$, vol. 13 , no. 3 , pp. $37-53$.

23. Isikoglu, M., Senol, Y., Berkkanoglu, M., Ozgur, K., Donmez, L. \& Stones-Abbasi, A. 2006, "Public opinion regarding oocyte donation in Turkey: First data from a secular population among the islamic world", Human Reproduction, vol. 21, no. 1, pp. 318-323.

24. Kadri, N., Berrada, S., Alami, K., Manoudi, F., Rachidi, L., Maftouh, S. \& Halbreich, U. 2007, "Mental health of Moroccan women, a sexual perspective", Journal of affective disorders, vol. 102, no. 0165-0327; 01650327; 1-3, pp. 199-207.

25. Khalili, M.A., Isikoglu, M., Tabibnejad, N., Ahmadi, M., Abed, F., Parsanejad, M.E., Ghasemi, M. \& el, J.H. 2008, "IVF staff attitudes towards oocyte donation: a multicentric study from Iran and Turkey", Reprod.Biomed.Online., vol. 17 Suppl 3, pp. 61-66.

26. Khuri, F.I. (ed) 2001, The Body in Islamic Culture, Saqi Books, London.

27. Korfker, D., Van Der Pal-de Bruin, K., Detmar, S. \& Buitendijk, S. October 2008, Problems in the treatment of infertility of Turkish and Moroccan couples; in Dutch: Knelpunten bij de behandeling van infertiliteit van Turken en Marokkanen, TNO, Leiden, Netherlands.

28. Lafta, R.K. 2006, "Practitioner gender preference among gynecologic patients in Iraq", Health care for women international, vol. 27, no. 2, pp. 125-130.

29. Larijani, B. \& Zahedi, F. 2007, "Ethical and religious aspects of gamete and embryo donation and legislation in Iran. [References]", J Relig Health, vol. 46, no. 3, pp. 399-408.

30. Meirow, D. \& Schenker, J.G. 1997, "Reproductive health care policies around the world. The current status of sperm donation in assisted reproduction technology: Ethical and legal considerations", Journal of assisted reproduction and genetics, vol. 14, no. 3, pp. 133-138. 
31. Ortner Sherry B. 2006, Anthropology and Social Theory; Culture, Power, and the Acting Subject, Duke University Press.

\section{Schenker, J.G. 2005, "Assisted reproductive practice: Religious perspectives", Reproductive BioMedicine Online, vol. 10, no. 3, pp. 310-319.}

33. Serour, G.I. 2008, "Islamic perspectives in human reproduction", Reprod.Biomed.Online., vol. 17 Suppl 3, pp. 34-38.

34. Serour, G.I. 1993, "Bioethics in artificial reproduction in the Muslim world", Bioethics., vol. 7, no. 2-3, pp. 207-217.

35. Serour, G.I., Aboulghar, M.A. \& Mansour, R.T. 1995, "Bioethics in medically assisted conception in the Muslim world", Journal of assisted reproduction and genetics, vol. 12, no. 9, pp. 559-565.

36. Serour, G.I. \& Dickens, B.M. 2001, "Assisted reproduction developments in the Islamic world", International Journal of Gynecology and Obstetrics, vol. 74, no. 2, pp. 187-193.

37. Simpson, B., Hampshire, K. \& Blell, M. 2012, British Pakistani Muslims, infertility and the new reproductive technologies: Summary of Findings, Durham University, Durham.

38. Smith, J.F., Eisenberg, M.L., Millstein, S.G., Nachtigall, R.D., Sadetsky, N., Cedars,
M.I. \& Katz, P.P. 2011, "Fertility treatments and outcomes among couples seeking fertility care: Data from a prospective fertility cohort in the United States", Fertility and sterility, vol. 95, no. 1, pp. 7984.

39. van Rooij, F.B., van Balen, F. \& Hermanns, J.M. 2009, "The experiences of involuntarily childless Turkish immigrants in the Netherlands", Qualitative health research, vol. 19, no. 5, pp. 621-632.

40. van Rooij, F. 2008, The experience of involuntarily childless Turkish migrants in the Netherlands: parenthood motives, psycho-social consequences, responses and help-seeking behavior, Faculty of Social and Behavioural sciences; SCO-Kohnstamm Instituut;University of Amsterdam.

41. van Rooij, F. \& Korfker, D. 2009, "Infertile Turkish and Moroccan Minority Groups in the Netherlands: Patients'Views on Problems within Infertility Care" in Marginalized Reproduction; Ethnicity, Infertility and Reproductve Technologies, eds. L. Culley, N. Hudson \& F. van Rooij, Earthscan, , pp. 134-150.

42. Yanikkerem, E., Özdemir, M., Bingol, H., Tatar, A. \& Karadeniz, G. 2009, "Women's attitudes and expectations regarding gynaecological examination", Midwifery, vol. 25, no. 5, pp. 500-508.

43. Yeprem, M.S. 2007, "Current assisted reproduction treatment practices from an Islamic perspective", Reproductive BioMedicine Online, vol. 14, pp. 44-47. 